\title{
Novel Oral Prostacyclin Analog With Thromboxane Synthase Inhibitory Activity for Management of Pulmonary Arterial Hypertension
}

\author{
Quang-Kim Tran, MD, PhD; Hiroshi Watanabe, MD, PhD
}

$\mathbf{P}$ ulmonary arterial hypertension (PAH) is a disease characterized by extensive remodeling of the small pulmonary arteries, resulting in increased elevated pulmonary arterial pressure and right ventricular heart failure. PAH is fatal if not treated, with only $34 \%$ survival rate after 5 years. ${ }^{1}$ Pathobiologically, PAH is the result of a combination of many factors. ${ }^{2}$ Simplistically, abnormal proliferation of endothelial cells is an important mechanism, which leads to increased arginase activity and downregulation of prostacyclin ( $\mathrm{PGI}$ ) synthase in lung tissues, and subsequent reduction in the production of the vasodilators nitric oxide (NO) and PGI $2 .{ }^{3-5}$ Endothelial hyperproliferation also increases the production of endothelin-1 (ET-1), one of the most potent vasoconstrictors. ET-1 overexpression in turns reduces the production of $\mathrm{NO}$ and PGI. These changes are associated with many other interrelated pathological changes, including vasoconstriction, hyper- proliferation of vascular smooth muscle cells and fibroblasts, vascular wall hypertrophy, inflammation, platelet aggregation, and thrombosis, all contributing to the remodeling of the pulmonary vasculature in PAH (Figure).

\section{Article p2127}

Based on these key features, currently approved therapies for PAH include phosphodiesterase 5 inhibitors (PDE-5I), endothelin-receptor antagonists (ERA) and PGI derivatives (Figure). PDE-5Is prevent cyclic GMP breakdown and therefore enhances the vasodilatory effect of $\mathrm{NO}$, ameliorating the effect of reduced NO production. ERAs prevent ET-1 interacting with its receptors, thereby alleviating the effects of excessive ET-1 in PAH patients. PGI2 derivatives increase the levels of PGI2, thereby alleviating the vasoconstriction caused by

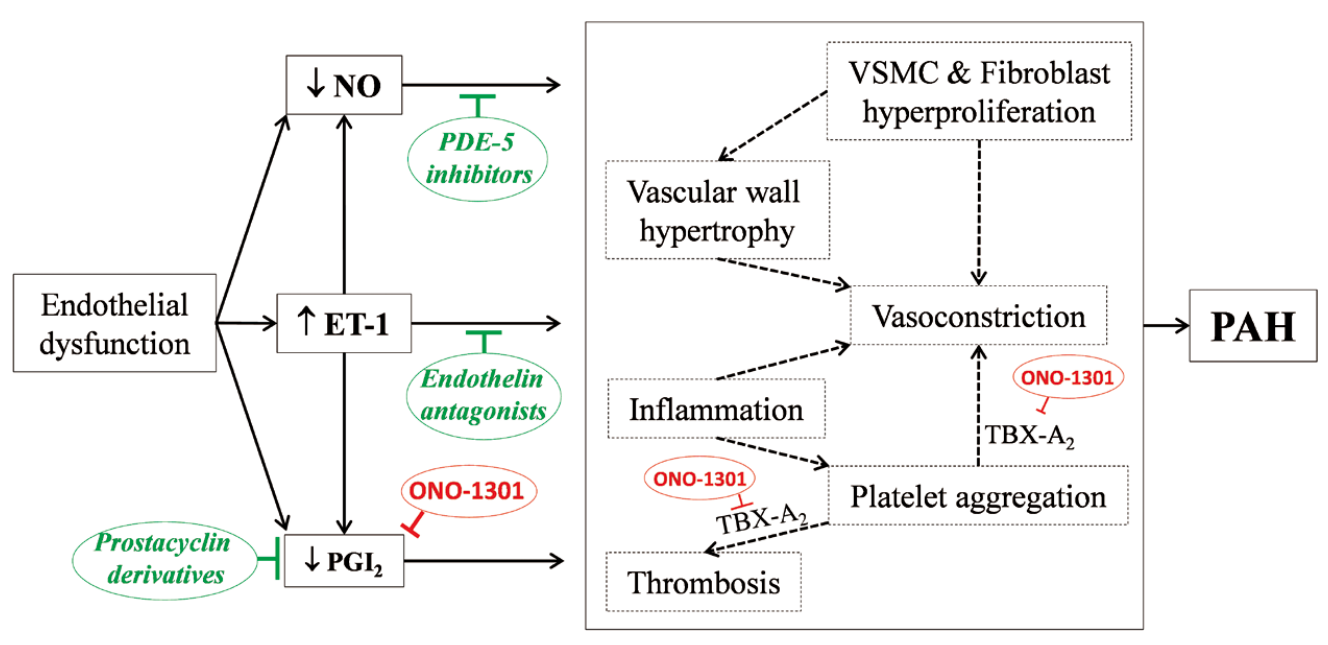

Figure. Key pathophysiologic pathways of pulmonary arterial hypertension (PAH) and therapeutic targets. ET, endothelin; NO, nitric oxide; $\mathrm{PGl}_{2}$, prostacyclin; TBXA2, thromboxane $\mathrm{A}_{2}$; VSMC, vascular smooth muscle cells. See text for explanation.

The opinions expressed in this article are not necessarily those of the editors or of the Japanese Circulation Society.

Received June 9, 2013; accepted June 10, 2013; released online June 25, 2013

Department of Physiology and Pharmacology, Des Moines University College of Osteopathic Medicine, Des Moines, IA (Q.-K.T.), USA; Department of Clinical Pharmacology \& Therapeutics, Hamamatsu University School of Medicine, Higashi-ku, Hamamatsu (H.W.), Japan

Mailing address: Quang-Kim Tran, MD, PhD, Department of Physiology \& Pharmacology, Des Moines University College of Osteopathic Medicine, 3200 Grand Avenue, Des Moines, IA 50312, USA. E-mail: kim.tran@dmu.edu or Hiroshi Watanabe, MD, PhD, Department of Clinical Pharmacology \& Therapeutics, Hamamatsu University School of Medicine, Handayama 1-20-1, Higashi-ku, Hamamatsu 431-3192, Japan. E-mail: hwat@hama-med.ac.jp

ISSN-1346-9843 doi:10.1253/circj.CJ-13-0738

All rights are reserved to the Japanese Circulation Society. For permissions, please e-mail: cj@j-circ.or.jp 
reduced concentrations of $\mathrm{PGI}_{2}$ in $\mathrm{PAH}$ patients. Generally, PDE-5Is and ERAs improve symptoms and survival; ${ }^{6,7}$ however, as the disease progresses, $\mathrm{PGI}_{2}$ derivatives are required, and there is evidence that disease progression and survival are improved by timely PGI 2 usage. ${ }^{8,9}$ Nonetheless, there are serious limitations to currently approved PGI 2 derivatives, ${ }^{10} \mathrm{a}$ major one being the instability of these drugs because of their metabolism by 15-hydroxyprostaglandin dehydrogenase, leading to short half-lives. As a result, they require inconvenient modes of administration, including subcutaneous or intravenous injection, or frequent sessions of inhalation, which greatly affects patient compliance.

In this issue of the Journal, Nakamura et al report on their testing of the effects of oral administration of ONO-1301, a $\mathrm{PGI}_{2}$ analog with inhibitory effects on thromboxane synthase, in rats with monocrotaline-induced PAH. ${ }^{11}$ ONO-1301 is a new compound with PGI2 activity (related to a carboxylic acid and lipid-soluble functional group that activate the $\mathrm{PGI}_{2}$ receptor), but is biologically stable because of the absence of prostanoid structures, including a 5-member ring and allylic alcohol. ${ }^{12}$ These characteristics give it a longer half-life of $5.6 \mathrm{~h}$, compared with $6 \mathrm{~min}$ for intravenous epoprostenol or $4 \mathrm{~h}$ for subcutaneous treprostinil. The compound also inhibits thromboxane synthase activity because of the presence of a 3-pyridine radical and a carboxylic acid. This inhibitory activity would add therapeutic benefit to $\mathrm{PGI}_{2}$ agonism, because it would not only further reduce vasoconstriction, but also help prevent thrombosis, an important pathophysiological feature of PAH (Figure). Subcutaneous ONO-1301 has been shown to reduce right ventricular pressure and pulmonary arterial medial wall thickness and improve survival in monocrotaline-induced PAH rats. ${ }^{12}$

Nakamura et al observed that following 16-24 days of twicedaily oral ONO-1301 administration, right ventricular pressure and medial pulmonary artery wall thickness were reduced using either a "preventive" or a "treatment" paradigm in the rat model of monocrotaline-induced PAH. ${ }^{11}$ ONO-1301 plasma levels were similar after a single oral or subcutaneous dose over the course of $24 \mathrm{~h}$. In addition, plasma cAMP rapidly increased after oral administration and remained elevated for up to $6 \mathrm{~h}$. Thromboxane synthase inhibition was demonstrated by decreases in urinary 11-dehydrothromboxane $\mathrm{B}_{2}$, a thromboxane A2 metabolite. Interestingly, an antibody against hepatic growth factor (HGF) appeared to negate the effects of ONO-1301 on survival, which corroborates previous observations that HGF improves survival of PAH rats via amelioration of pulmonary hemodynamics, ${ }^{13}$ and suggests an interesting possibility that reduction in HGF production may be a factor in the pathogenesis of PAH. Detailed mechanisms of this putative involvement are yet to be defined.

Importantly, Nakamura et al observed that survival rates were not different among PAH rats under similar durations of monotherapy with oral ONO-1301, PDE-5I, sildenafil, or ERA, bosentan. An oral formulation of the $\mathrm{PGI}_{2}$ derivative, treprostinil, has recently been intensively investigated as single therapy in multicenter clinical trials of PAH patients (FREEDOM-M $)^{14}$ or as combined therapy on the background PDE-5I and/or ERA therapy (FREEDOM-C2). ${ }^{15}$ Those trials have demonstrated that although monotherapy with oral treprostinil improved exercise capacity, with the dosing regimens tested it does not appear to have additional benefit to PDE-5I or ERA in the combination regimens. Although ONO-1301 has yet to be tested on human subjects, with its additional inhibitory effect on thromboxane synthase activity, it will be very interesting to investi- gate if ONO-1301 has additional effects on the hemodynamics and survival of PAH subjects when used in combination with PDE-5I and/or ERA therapy.

\section{Acknowledgments}

The laboratory of Q.-K. Tran is supported by the US National Heart, Lung, and Blood Institute, National Institutes of Health. H. Watanabe has received research funding from the Ministry of Health, Labor and Welfare of Japan, Teika Seiyaku, Takeda Pharmaceuticals, Mochida, Pfizer, Asteras and Daiichi Sankyo, and lecture fees from Pfizer, Acterion and Nihon Shinyaku.

\section{References}

1. D'Alonzo GE, Barst RJ, Ayres SM, Bergofsky EH, Brundage BH, Detre KM, et al. Survival in patients with primary pulmonary hypertension: Results from a national prospective registry. Ann Intern Med 1991; 115: 343-349.

2. Schermuly RT, Ghofrani HA, Wilkins MR, Grimminger F. Mechanisms of disease: Pulmonary arterial hypertension. Nat Rev Cardiol $2011 ; 8: 443-455$.

3. Xu W, Kaneko FT, Zheng S, Comhair SA, Janocha AJ, Goggans T, et al. Increased arginase II and decreased NO synthesis in endothelial cells of patients with pulmonary arterial hypertension. FASEB $J$ 2004; 18: 1746-1748.

4. Tuder RM, Cool CD, Geraci MW, Wang J, Abman SH, Wright L, et al. Prostacyclin synthase expression is decreased in lungs from patients with severe pulmonary hypertension. Am J Respir Crit Care Med 1999; 159: 1925-1932.

5. Badesch DB, Orton EC, Zapp LM, Westcott JY, Hester J, Voelkel $\mathrm{NF}$, et al. Decreased arterial wall prostaglandin production in neonatal calves with severe chronic pulmonary hypertension. Am J Respir Cell Mol Biol 1989; 1: 489-498.

6. Watanabe H, Ohashi K, Takeuchi K, Yamashita K, Yokoyama T, Tran $\mathrm{QK}$, et al. Sildenafil for primary and secondary pulmonary hypertension. Clin Pharmacol Ther 2002; 71: 398-402.

7. Satoh T, Saji T, Watanabe H, Ogawa S, Takehara K, Tanabe N, et al. A phase III, multicenter, collaborative, open-label clinical trial of sildenafil in Japanese patients with pulmonary arterial hypertension. Circ J 2011; 75: 677-682.

8. McLaughlin VV, Archer SL, Badesch DB, Barst RJ, Farber HW, Lindner JR, et al. ACCF/AHA 2009 expert consensus document on pulmonary hypertension a report of the American College of Cardiology Foundation Task Force on Expert Consensus Documents and the American Heart Association developed in collaboration with the American College of Chest Physicians, American Thoracic Society, Inc., and the Pulmonary Hypertension Association. J Am Coll Cardiol 2009; 53: 1573-1619.

9. Barst RJ, Gibbs JS, Ghofrani HA, Hoeper MM, McLaughlin VV, Rubin LJ, et al. Updated evidence-based treatment algorithm in pulmonary arterial hypertension. J Am Coll Cardiol 2009; 54: S78-S84.

10. Waxman AB, Zamanian RT. Pulmonary arterial hypertension: New insights into the optimal role of current and emerging prostacyclin therapies. Am J Cardiol 2013; 111: 1A-16A; quiz 17A-19A.

11. Nakamura A, Nagaya N, Obata H, Sakai K, Sakai Y, Yoshikawa M, et al. Oral Administration of a novel long-acting prostacyclin agonist with thromboxane synthase inhibitory activity for pulmonary arterial hypertension. Circ J 2013; 77: 2127-2133.

12. Kataoka M, Nagaya N, Satoh T, Itoh T, Murakami S, Iwase T, et al. A long-acting prostacyclin agonist with thromboxane inhibitory activity for pulmonary hypertension. Am J Respir Crit Care Med 2005; 172: $1575-1580$.

13. Hiramine K, Sata N, Ido A, Kamimura R, Setoyama K, Arai K, et al. Hepatocyte growth factor improves the survival of rats with pulmonary arterial hypertension via the amelioration of pulmonary hemodynamics. Int J Mol Med 2011; 27: 497-502.

14. Jing ZC, Parikh K, Pulido T, Jerjes-Sanchez C, White RJ, Allen R, et al. Efficacy and safety of oral treprostinil monotherapy for the treatment of pulmonary arterial hypertension: A randomized, controlled trial. Circulation 2013; 127: 624-633.

15. Tapson VF, Jing ZC, Xu KF, Pan L, Feldman J, Kiely DG, et al. Oral treprostinil for the treatment of pulmonary arterial hypertension in patients on background endothelin receptor antagonist and/or phosphodiesterase type 5 inhibitor therapy (The FREEDOM-C2 Study): A randomized controlled trial. Chest 2013 May 9, doi:10.1378/chest.122875 . 